\title{
Retinal microvascular parameters are not significantly associated with mild cognitive impairment in the Northern Ireland Cohort for the Longitudinal Study of Ageing
}

R. A. O'Neill, A. P. Maxwell, E. N. Paterson, F. Kee, I. Young, R. E. Hogg, S. Cruise, S. Murphy, B. McGuinness and G. J. McKay ${ }^{*}$ D

\begin{abstract}
Background: The retinal and cerebral microvasculature share similar embryological origins and physiological characteristics. Improved imaging technologies provide opportunistic non-invasive assessment of retinal microvascular parameters (RMPs) against cognitive outcomes. We evaluated baseline measures for associations between RMPs and mild cognitive impairment (MCl) from participants of the Northern Ireland Cohort for the Longitudinal Study of Ageing (NICOLA).

Methods: RMPs (central retinal arteriolar / venular equivalents, arteriole to venular ratio, fractal dimension and tortuosity) were measured from optic disc centred fundus images and analysed using semi-automated software. Associations between RMPs and $\mathrm{MCl}$ were assessed by multivariable logistic regression with adjustment for potential confounders including age, sex, alcohol consumption, smoking status, educational attainment, physical activity, cardiovascular disease (CVD), hypertension, mean arterial blood pressure, triglycerides, diabetes, body mass index, and high density lipoprotein levels. $P<0.05$ was considered statistically significant.

Results: Data were available for 1431 participants, of which 156 (10.9\%) were classified with MCl defined by a Montreal Cognitive Assessment (MoCA) score $\leq 26$, with subjective cognitive decline, in the absence of depression or problems with activities of daily living. Participants had a mean age of $62.4 \pm 8.5 \mathrm{yrs}$. and $52 \%$ were female. As expected, individuals with $\mathrm{MCl}$ had a lower MoCA score than those without ( $23.5 \pm 2.6$ versus $26.3 \pm 2.7$, respectively), were more likely to be female, have a lower level of educational attainment, be less physically active, more likely to have CVD, have higher levels of triglycerides and lower levels of high density lipoprotein. No significant associations between RMPs and MCI were detected in unadjusted, minimally adjusted or fully adjusted regression models or subsequent sensitivity analyses.
\end{abstract}

Conclusion: Previous studies have reported both increased retinal venular calibre and reduced fractal dimension in association with mild cognitive impairment. Our study failed to detect any associations between RMPs and those individuals at an early stage of cognitive loss in an older community-based cohort.

Keywords: Retinal microvascular parameters, Cognitive function, Mild cognitive impairment, The Montreal cognitive assessment

\footnotetext{
*Correspondence: g.j.mckay@qub.ac.uk

Centre for Public Health, Queens University Belfast, Belfast, Northern Ireland
} 


\section{Background}

Population ageing has resulted in increased prevalence of age-related conditions that negatively impact healthcare systems, policies and demands, primarily as a consequence of reduced mortality [1,2]. The most rapidly growing demographic in Northern Ireland (NI) is those aged $>50$ years (yrs), necessitating improved understanding of the impact of age-related conditions [3]. Cognitive impairment significantly impacts activities of daily living (ADL), especially among the aged $[4,5]$. During the ageing process, cognitive skills such as conceptual reasoning, memory, and processing speed decline. Some individuals may exceed a threshold characterised as mild cognitive impairment (MCI), which may progress to dementia in up to $50 \%$ of cases over 5 years [6-11]. MCI is characterised by subtle changes in cognitive function, although everyday life generally remains largely unaffected. Severe cognitive impairment that leads to dementia results in an extensive loss of cognitive ability and ultimately, independent living [12]. Given life expectancy has increased globally, an improved understanding of normal ageing processes will advance measures of successful and healthy ageing and differentiation of normal and diseased states [13, 14].

The characteristic disease aetiology of MCI is not fully understood, despite its influence on increased morbidity among the elderly. Cerebral microvascular disease has previously been associated with an increased risk of both MCI and Alzheimer's disease [15-19], possibly through common microvascular factors such as hypertension, diabetes, smoking and inflammation [20-22]. Furthermore, variation in cerebral microvascular characteristics, such as increased tortuosity and arteriolar narrowing, have been reported in association with degenerative changes during the onset of dementia [23, 24]. The retinal and cerebral microvasculature share similar embryological origins and physiological characteristics [25], and advanced retinal imaging has facilitated the non-invasive assessment of associations between retinal microvascular parameters (RMPs) and cognitive function [25-29]. Previously, reduced retinal microvascular calibre and fractal dimension have been reported in association with cognitive impairment with suggestions that this may reflect cerebral microvascular variation, especially in older adults [30, 31]. The aim of this study was to evaluate associations between RMPs and MCI in the Northern Ireland Cohort for the Longitudinal Study of Ageing (NICOLA).

\section{Methods}

\section{Study population}

NICOLA is a longitudinal cohort study of 8468 participants aged 50 years and over, living in the Northern Ireland community (individuals in care homes or other residential institutions were excluded [32, 33];). The study was established in 2012 with three main components: a computer-aided personal interview (CAPI), a self-completion questionnaire and health assessment. The CAPI extensively assessed demographic, social and health-related factors. Biological samples and measures of cardiovascular, physical, cognitive and visual function, including retinal fundus photography, were collected. Ethical approval was provided by the School of Medicine, Dentistry and Biomedical Sciences Ethics Committee, Queen's University Belfast and written informed consent obtained prior to participation, in accordance with the Declaration of Helsinki (SREC 12/23).

\section{Measurement of cognitive function and classification of $\mathrm{MCl}$}

Data was available for 3741 participants that attended a health assessment which included a 30 point Montreal Cognitive Assessment (MoCA) to evaluate cognitive function. This included a short-term memory recall task, assessment of visuospatial abilities and executive function, a phonemic fluency task, and a two-item verbal abstraction task. Attention, concentration, language, orientation to time and working memory were also assessed [13]. An extra point was added to the MoCA test score for participants with less than 12 years of formal education. Participants were investigated for subjective cognitive decline (SCD) and a series of questions based on difficulties associated with basic ADL, such as dressing, walking, bathing or showering, eating, getting in or out of bed, and using the toilet. SCD was assessed qualitatively at CAPI by participant response to a five point rating of their day-to-day memory with fair to poor, the least favourable options, characterised as SCD. Participants also completed the Centre for Epidemiologic Studies Depression Scale questionnaire (CES-D) which consisted of 20 questions that were scored from 0 to 3 , to assess depressive symptoms. Summative scores ranged from 0 to 60 , with values $\geq 16$ indicative of depression (DEPR [34];). Individuals who failed to complete the MoCA, reported difficulties with ADL activities, and had DEPR (CES-D $\geq 16)$ or retinal images of insufficient quality, were excluded from the analysis. MCI was defined as a combination of MoCA test score $\leq$ 26 with SCD, in the absence of DEPR or problems with ADL activities. In a sensitivity analysis, a stricter $\mathrm{MCI}$ definition used a MoCA score $\leq 23$ in the presence of SCD or problems with ADL activities and the absence of DEPR.

\section{Other variables}

Mean arterial blood pressure (MABP), was taken as the average of two individual systolic blood pressure (SBP) and diastolic blood pressure (DBP) measurements $(2 / 3$ 
DBP $+1 / 3$ SBP). Diabetic status was defined using a combination of participant percentage haemoglobin A1c (HbA1c $>6.5 \%)$, diabetic medication use or self-reported diabetes. Cardiovascular disease (CVD) was by selfreport and included a history of angina, heart attack, congestive heart failure or stroke. Educational attainment was dichotomised on the basis of primary or secondary level education and above (including university education). Smoking status was dichotomised as current versus non-smoker. Alcohol consumption was categorised into four groups; non-drinker, light drinker (0-7 units per week), moderate drinker (7-14 units per week) and heavy drinker (>14 units per week). Physical activity (PA) was categorised as low, moderate or highly active in accordance with the Global Physical Activity Questionnaire (GPAQ) by calculating the average time per day spent in each activity domain (work, transport and leisure) and the intensity of that time spent [35, 36]. Hypertension was categorised on the basis of self-report or use of antihypertensive medication.

\section{Measurement of retinal images}

Retinal photography was undertaken following dilation from a single drop of $1 \%$ tropicamide using a Canon CX-1 Digital Fundus Camera (Canon USA, Melville, NY, USA). RMPs included central retinal arteriolar equivalent (CRAE), central retinal venular equivalents (CRVE), arteriole to venular ratio (AVR), fractal dimension and tortuosity quantified from optic disc centred fundus images using the semi-automated software Vessel Assessment and Measurement Platform for Images of the Retina (VAMPIRE; VAMPIRE group, University of Dundee, Dundee, Scotland, Version 3.1, Fig. 1), by a trained grader that was blinded to participant data [37, 38]. Analysis was performed mostly on left eye retinal images except when unavailable or of insufficient quality, in which case right eye images was used. A paired samples t-test was used to compare a sub-sample of left and right eye measures from 75 participants. Intraclass correlation coefficients (ICCs) were compared to determine intergrader reliability with mean values of 0.87 (CRAE) and 0.91 (CRVE).

\section{Statistical analysis}

All statistical tests were completed using Statistical Package for Social Sciences (Version 24.0. Armonk, NY: IBM Corp). All RMPs were transformed into standardised Z-scores (a standard deviation [SD] increase or decrease from the mean) before consideration within regression models. Population summary measures were described using mean and SD for continuous variables or frequencies and percentages for categorical variables. Independent samples t-tests and chi-squared tests compared the distribution of participant characteristics with and without MCI. Logistic regression evaluated associations between RMPs and MCI status categorised as a binary trait. Minimally adjusted models included age and sex, while fully adjusted models also included alcohol consumption, smoking status, educational attainment, PA, CVD, hypertension, MABP, triglycerides, diabetes, body mass index (BMI) and high density lipoprotein (HDL). $P<0.05$ was considered statistically significant.

\section{Results}

Data were available for 1431 participants who met the study inclusion criteria (Fig. 2). There were 156 (10.9\%) and 1275 (89.1\%) participants classified with and without MCI respectively. Participants had a mean age of $62.4 \pm$ 8.5 yrs. and $52 \%$ were female, with $87 \%$ categorised with an educational attainment of secondary level or above (including higher education and university; Table 1). The mean MoCA score for all participants was $26.0 \pm$ 2.8. MABP was $98.1 \pm 12.6 \mathrm{mmHg}$, and 22,6 and $30 \%$ of participants were characterised with diabetes, CVD and hypertension, respectively. Individuals with MCI had a lower MoCA score than those without $(23.5 \pm 2.6$ versus $26.3 \pm 2.7$, respectively), had a higher mean age (64.4 \pm 8.8 yrs. versus $62.1 \pm 8.4 \mathrm{yrs}$ ) and a lower percentage were female ( $45 \%$ versus $53 \%$, respectively). Those with MCI had higher mean triglycerides $(1.8 \pm 1.2 \mathrm{mmol} / \mathrm{L}$ versus $1.6 \pm 0.9 \mathrm{mmol} / \mathrm{L}$, respectively) and evidence of CVD (12\% versus 6\%). Those without MCI had higher mean HDL cholesterol $(1.7 \pm 0.5 \mathrm{mmol} / \mathrm{L}$ versus $1.6 \pm$ $0.4 \mathrm{mmol} / \mathrm{L}$, respectively) and educational attainment (89\% versus $76 \%$, Table 1 ).

Left and right eye CRAE and CRVE measures from 75 participants were not significantly different $\left(\mathrm{P}_{\mathrm{Crae}}=0.08\right.$; $P_{\text {Crve }}=0.89$ ). No significant associations between RMPs and MCI in unadjusted (Table 2), minimally adjusted (which included age and sex) or fully adjusted comparisons (which also included alcohol consumption, smoking status, educational attainment, PA, CVD, hypertension, MABP, triglycerides, diabetes, BMI, and HDL; Table 3).

A sensitivity analysis to examine a more severe MCI phenotype defined by a MoCA threshold $\leq 23$ in the presence of SCD or problems with ADL activities and the absence of DEPR reclassified some of the 1431 participants characterising 61 (4.3\%) and 1370 (95.7\%) with and without $\mathrm{MCI}$, respectively. As expected, individuals with MCI had a lower MoCA score than those without (20.8 \pm 2.0 versus $26.2 \pm 2.7$, respectively), had a higher mean age $(66.4 \pm 9.4$ yrs. versus $62.2 \pm 8.4 \mathrm{yrs})$ and lower percentage female ( $43 \%$ versus $53 \%$, respectively; Supplementary Table 1). AVR was significantly associated with MCI in unadjusted (Supplementary Table 2) and minimally adjusted models (which included age and sex; $P=$ 0.04), but did not survive full adjustment for age, sex, alcohol consumption, smoking status, educational 


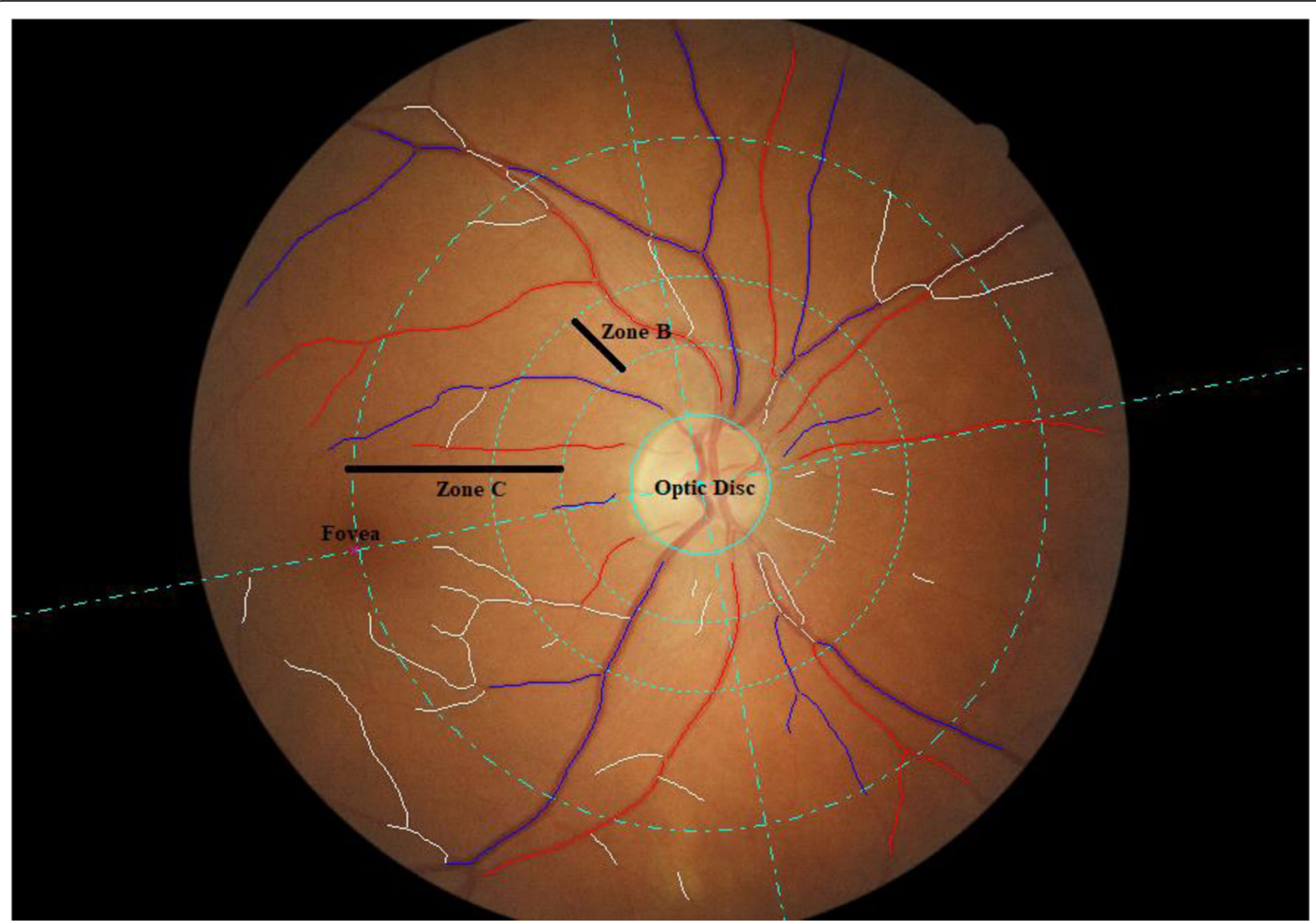

Fig. 1 Retinal fundus image assessment using VAMPIRE software. Optic disc centred retinal fundus image assessment using the Vessel Assessment and Measurement Platform for Images of the Retina (VAMPIRE) software. Arterioles (red), venules (blue) and deleted segments (white) are indicated. The retinal microvascular parameters for arteriolar and venular calibre (CRAE, CRVE, and AVR), are calculated from measurements captured in zones B (1.0 to 1.5 optic disc diameters from the centre of the optic disc). Fractal dimension and tortuosity are calculated from measurements captured in zone C (1.0 to 2.5 optic disc diameters from the centre of the optic disc)

attainment, PA, CVD, hypertension, MABP, triglycerides, diabetes, BMI and HDL $(P>0.05$; Supplementary Table 3). No further significant associations were detected between RMPs and MCI in unadjusted (Supplementary Table 2), minimally adjusted or fully adjusted comparisons $(P>0.05$; Supplementary Table 3$)$.

\section{Discussion}

Advances in imaging technologies have enabled in vivo non-invasive, opportunistic, quantitative evaluation of retinal characteristics with vascular health [39]. Previous population-based studies reported associations between RMPs and MCI $[15,29,30]$ although these have been mostly limited to vessel calibre with several also considering fractal dimension and tortuosity [31, 40]. A recent systematic review and meta-analysis of five studies reported associations between decreased arteriolar and venular fractal dimension and cognitive impairment [41]. The case definitions used in all five studies were variable and included a significant proportion of participants with more advanced dementia [41]. Although, we were unable to replicate their findings, the direction of effect observed in our study were similar, despite the less severe phenotype within our population-based study.

Liew and colleagues characterised 121 participants with MCI (6.1\%) according to a Mini Mental State Examination (MMSE) threshold $\leq 23$ from 1988 participants aged 49-97 yrs. from the cross-sectional population-based Blue Mountain Eye Study. They reported associations between wider venular calibre and cognitive impairment, the strongest being in persons with hypertension, and hypothesised this may reflect cerebral venular narrowing associated with cognitive decline [30]. In contrast, we found little support of association between CRVE and $\mathrm{MCI}$ in the current study (OR $=0.96 ; 95 \%$ CI: $0.81,1.15 ; P=0.68$ ). Other studies have suggested a MoCA threshold of 26 may limit the specificity of cognitive assessment through an over 


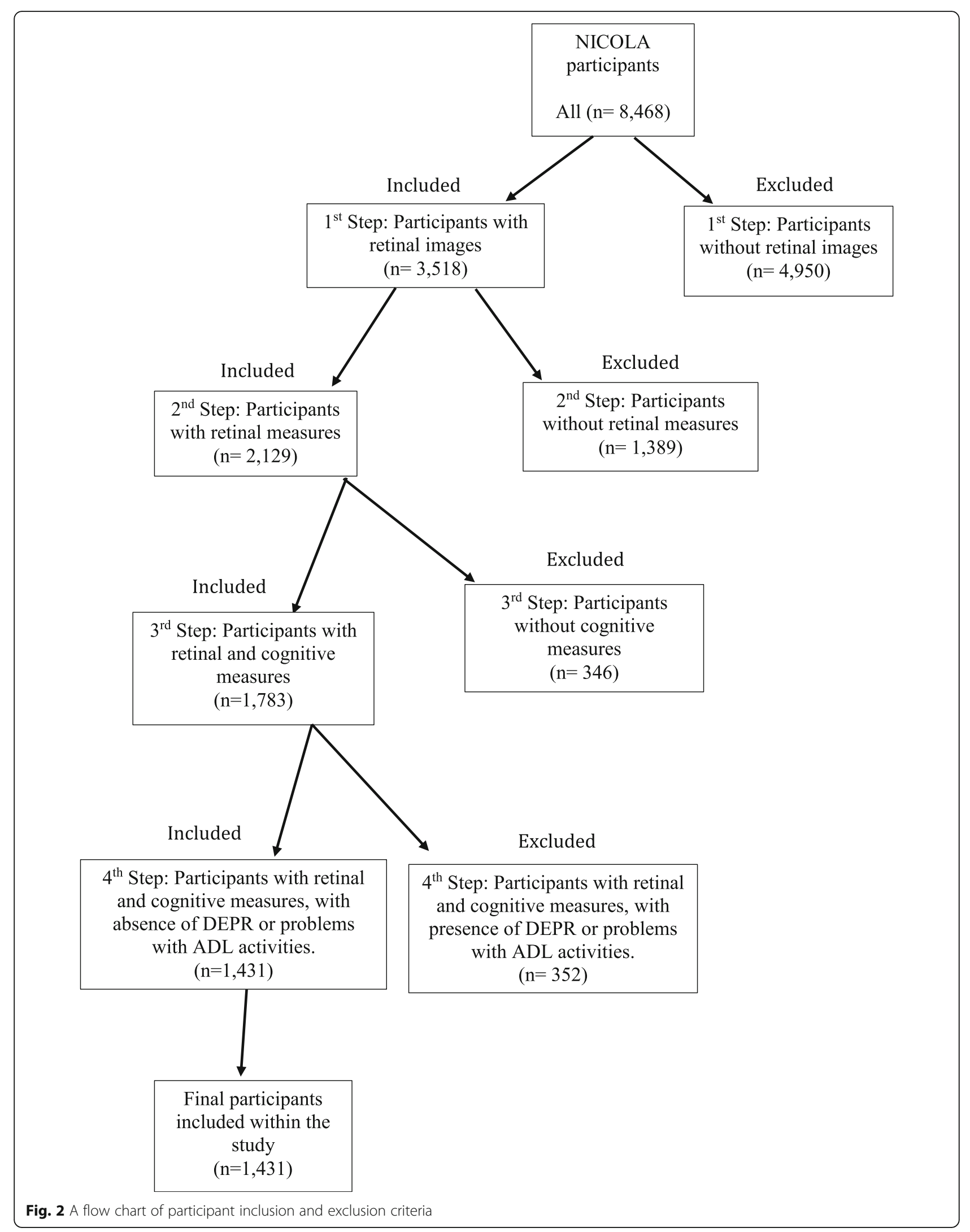


Table 1 Participant summary characteristics

\begin{tabular}{|c|c|c|c|c|}
\hline Patient characteristics & All $(n=1431)$ & No $\mathrm{MCl}(n=1275)$ & $\mathrm{MCl}(n=156)$ & $P$-Value \\
\hline Mean age (years, SD) & $62.4 \pm 8.5$ & $62.1 \pm 8.4$ & $64.4 \pm 8.8$ & $<0.01$ \\
\hline Female, n (\%) & $750(52.4)$ & $680(53.3)$ & $70(44.9)$ & 0.05 \\
\hline Smoking status, yes n (\%) & $115(8.0)$ & $101(7.9)$ & $14(9.0)$ & 0.65 \\
\hline Alcohol consumption, non-drinker, n (\%) & $299(20.9)$ & $261(20.5)$ & $38(24.4)$ & 0.63 \\
\hline Education, secondary level and above, n (\%) & $1251(87.4)$ & $1133(88.9)$ & $118(75.6)$ & $<0.01$ \\
\hline Physical activity level, highly active, n (\%) & $438(30.6)$ & $405(31.8)$ & $33(21.2)$ & 0.04 \\
\hline Diabetes, yes n (\%) & $308(21.5)$ & $275(21.6)$ & $33,921.2)$ & 0.91 \\
\hline Mean BMI $\left(\mathrm{kg} / \mathrm{m}^{2}, \mathrm{SD}\right)$ & $28.2 \pm 4.6$ & $28.1 \pm 4.6$ & $28.9 \pm 4.5$ & 0.03 \\
\hline Mean arterial blood pressure (mmHg, SD) & $98.1 \pm 12.6$ & $98.2 \pm 12.6$ & $97.1 \pm 12.5$ & 0.30 \\
\hline Cardiovascular disease, yes n (\%) & $90(6.3)$ & $72(5.6)$ & $18(11.5)$ & $<0.01$ \\
\hline Hypertension, yes n (\%) & $432(30.2)$ & $372(29.2)$ & $60(38.5)$ & 0.02 \\
\hline Mean triglyceride (mmol/L, SD) & $1.6 \pm 0.9$ & $1.6 \pm 0.9$ & $1.8 \pm 1.2$ & 0.01 \\
\hline Mean HDL cholesterol (mmol/L, SD) & $1.6 \pm 0.5$ & $1.7 \pm 0.5$ & $1.6 \pm 0.4$ & 0.02 \\
\hline Mean MOCA test score (SD) & $26.0 \pm 2.8$ & $26.3 \pm 2.7$ & $23.5 \pm 2.6$ & $<0.01$ \\
\hline
\end{tabular}

Values are $\mathrm{n}(\%)$ for categorical variables and mean \pm SD for continuous variables. $P$ values were calculated by independent samples $\mathrm{t}$ and chi squared tests. Abbreviations: $M C l$ mild cognitive impairment, BMI body mass index, HDL high-density lipoprotein, MoCA Montreal Cognitive Assessment, SD standard deviation. $P<0.05$ was considered statistically significant

estimation of those affected [42-46]. Interestingly, a recent meta-analysis reported improved diagnostic accuracy using a MoCA threshold $\leq 23$ to reduce the number of false-positive MCI participants [47]. In addition, our findings also failed to support the previously reported associations between retinal arteriolar narrowing in 809 older Latinos [48]. To improve the sensitivity of the MCI definition in our study, those with DEPR were excluded and the MoCA threshold reduced $\leq 23$ in the presence of SCD or problems with ADL activities. This sensitivity analysis also failed to detect any significant associations between RMP and MCI (Supplementary Tables 1, 2 and 3). Further analyses that used an MCI definition not constrained by the presence of DEPR (CES-D score $\geq 16$ ), also failed to identify any significant associations in a fully adjusted binary logistic regression model that also included CES-D score as a covariate (data not shown).

Our study had several strengths including the large population-based study design. The participants were well-characterised, with a significant number of potential confounders considered, including demographic factors, clinical variables, co-morbidities and medications. Furthermore, the availability of optic disc centred retinal fundus images provided a more accurate quantification of RMPs compared to macula centred images, which often limit assessment to the retinal temporal arcades. In this study, retinal images from the left eye were analysed except when unavailable or of insufficient quality, in which case right eye images, were used. Use of data from a single eye is unlikely to have limited the study outcomes, as similar investigations have previously reported

Table 2 Summary of participant retinal microvascular parameters

\begin{tabular}{lllll}
\hline Retinal microvascular parameters & All $(\boldsymbol{n}=\mathbf{1 4 3 1})$ & No $\mathbf{M C l}(\boldsymbol{n}=\mathbf{1 2 7 5})$ & MCI $(\boldsymbol{n}=\mathbf{1 5 6})$ & $29.731 \pm 2.294$ \\
\hline Mean CRAE (PX, SD) & $29.643 \pm 2.221$ & $29.632 \pm 2.213$ & $40.723 \pm 3.059$ \\
Mean CRVE (PX, SD) & $40.844 \pm 3.268$ & $40.858 \pm 3.293$ & $0.733 \pm 0.064$ & 0.60 \\
Mean AVR (SD) & $0.729 \pm 0.061$ & $0.728 \pm 0.061$ & $1.555 \pm 0.053$ & 0.62 \\
Mean fractal dimension arteriolar (SD) & $1.557 \pm 0.053$ & $1.557 \pm 0.053$ & $1.539 \pm 0.052$ & 0.38 \\
Mean fractal dimension venular (SD) & $1.540 \pm 0.051$ & $1.540 \pm 0.050$ & $0.128 \pm 0.162$ & 0.78 \\
${ }^{\text {M} M e a n ~ t o r t u o s i t y ~ a r t e r i o l a r ~(S D) ~}$ & $0.114 \pm 0.157$ & $0.112 \pm 0.157$ & $0.063 \pm 0.056$ \\
\hline${ }^{a}$ Mean tortuosity venular (SD) & $0.067 \pm 0.106$ & $0.068 \pm 0.111$ & 0.24 \\
\hline
\end{tabular}

Values are $\mathrm{n}(\%)$ for categorical variables and mean \pm SD for continuous variables. $P$ values were calculated by independent samples $\mathrm{t}$ tests. Abbreviations: $M C I$ mild cognitive impairment, CRAE central retinal arteriolar equivalent, CRVE central retinal venular equivalent, $A V R$ retinal arteriole/venular ratio, SD standard deviation, PX Pixels. ${ }^{a}$ Tortuosity values were multiplied by 1000 in order to be shown in Table. $P<0.05$ was considered statistically significant 
Table 3 Logistic regression analysis of retinal microvascular parameters and Mild Cognitive Impairment status

\begin{tabular}{|c|c|c|c|c|c|c|}
\hline \multirow[t]{2}{*}{ Retinal parameter } & \multicolumn{3}{|c|}{ Minimally Adjusted } & \multicolumn{3}{|c|}{ Fully Adjusted } \\
\hline & OR & $95 \% \mathrm{Cl}$ & $P$-Value & $\mathrm{OR}$ & $95 \% \mathrm{Cl}$ & $P$-Value \\
\hline${ }^{\mathrm{a}}$ CRAE (PX) & 1.04 & $0.88,1.23$ & 0.66 & 1.04 & $0.88,1.24$ & 0.63 \\
\hline${ }^{\mathrm{a}}$ CRVE (PX) & 0.95 & $0.80,1.12$ & 0.53 & 0.96 & $0.81,1.14$ & 0.67 \\
\hline${ }^{\mathrm{a}} \mathrm{AVR}$ & 1.08 & $0.92,1.28$ & 0.35 & 1.07 & $0.90,1.28$ & 0.42 \\
\hline aFractal dimension arteriolar & 0.98 & $0.83,1.15$ & 0.80 & 0.93 & $0.79,1.10$ & 0.42 \\
\hline${ }^{\mathrm{a}}$ Fractal dimension venular & 1.00 & $0.85,1.18$ & 0.98 & 0.97 & $0.82,1.15$ & 0.69 \\
\hline${ }^{\mathrm{ab}}$ Tortuosity arteriolar & 1.12 & $0.95,1.32$ & 0.19 & 1.09 & $0.92,1.29$ & 0.30 \\
\hline${ }^{\mathrm{ab}}$ Tortuosity venular & 0.97 & $0.82,1.15$ & 0.76 & 0.97 & $0.82,1.16$ & 0.75 \\
\hline
\end{tabular}

Abbreviations: CRAE central retinal arteriolar equivalent, CRVE central retinal venular equivalent, $A V R$ retinal arteriole/venular ratio, $C I$ confidence interval, $O R$ odds ratio, $P X$ pixels. ${ }^{\mathrm{a}} \mathrm{RMPs}$ were transformed into standardised Z-scores before inclusion in regression models. ${ }^{\mathrm{b}}$ Tortuosity values were skewed and therefore logtransformed before inclusion in regression models. Minimally adjusted model: age and sex. Fully adjusted model: age, sex, alcohol consumption, smoking status, educational attainment, physical activity, history of cardiovascular disease, hypertension, triglycerides, diabetes, medication, mean arterial blood pressure, body mass index and high density lipoprotein. $P<0.05$ was considered statistically significant

high bilateral RMP comparisons [49-51], similarly supported by data from a subset of NICOLA participants.

Characterisation of MCI (based on MoCA $\leq 26$ and SCD with no limitations in ADL, independent of DEPR) was well defined and in line with similar studies [52]. The MoCA was better suited to our study population as it was primarily developed as a valid and reliable screening tool for $\mathrm{MCI}$, in turn, offering greater sensitivity and specificity in comparison to the MMSE [13, 44, 53, 54]. Previous studies have suggested MoCA offers improved sensitivity for the characterisation of $\mathrm{MCI}$, dementia, Alzheimer's disease, stroke and Parkinson's disease [13, 43, 44, 53, 55-58]. Exclusion of participants with DEPR further improved the accuracy of MCI characterisation, given those with depressive symptoms are more likely to score poorly in a MoCA [59]. Furthermore, differences between mild and major neurocognitive disorders are determined by the degree to which cognitive decline restricts daily functioning. In major neurocognitive disorders or dementia, cognitive impairment negatively impacts independence in basic ADLs such as walking, bathing and eating. In comparison, those with mild neurocognitive disorders or $\mathrm{MCI}$, largely remain selfsufficient, although subtle problems may arise in complex activities (instrumental ADLs) [60]. Therefore, the exclusion of individuals reporting difficulties with basic ADLs strengthens the MCI definition and reduces the likelihood of including those with more advanced cognitive impairment.

The NICOLA participants were aged 50 yrs. and above, with a mean age of 62 years, thereby limiting the number of participants with MCI. In the Cardiovascular Health Study, MCI prevalence increased from 19\% in participants $<75$ yrs. to $29 \%$ in those 85 yrs. and older [61]. Kumar and colleagues reported lower MCI prevalence in participants aged 60 to 64 yrs. (3.7\%), a demographic similar to our study [62]. Tyrovolas and colleagues, reported MCI prevalence of $10.1 \%$ in 5364 participants of the Irish Longitudinal Study on Ageing (TILDA), not dissimilar to the comparably aged NICOLA participants in the current study (10.9\%) [52].

Our study had some limitations. Although NICOLA is a longitudinal study, only baseline data were available for the present analysis. The largely Caucasian study participants aged $\geq 50$ yrs. excluded institutionalised individuals and those with dementia and may represent the 'worried-well', i.e. those that attended the health assessment were more likely to have been conscious about their health, thereby limiting the generalisability of our findings to the wider population. Despite adjustment for potential confounders, the possibility of residual confounding remains. Retinal imaging and cognitive function measures were only available for the 1431 participants that met the inclusion criteria which represented only $38 \%$ of those that attended for health assessment and may represent a further source of selection bias (Supplementary Table 4). It was not feasible to undertake a formal neuropsychological assessment within the NICOLA study. We determined MCI using the most robust measures of cognition (MoCA), subjective concerns (SCD), function (ADLs) and depressive symptoms (CES-D) available. Finally, MCI is not consistently characterised across all population-based studies, although our definition was comparable to similar studies [52].

\section{Conclusion}

The increasing prevalence of MCI highlights the importance of sufficient provision within healthcare systems for the early identification of at risk individuals in this emerging public health problem. Despite previously reported associations between wider retinal venular calibre and reduced measures of retinal fractal dimension and $\mathrm{MCI}$, we were unable to find any supporting evidence that variation in retinal microvascular parameters might help identify those individuals at increased risk. 


\section{Abbreviations}

NICOLA: The Northern Ireland Cohort for the Longitudinal Study of Ageing; BMI: Body mass index; HDL: High-density lipoprotein; CRAE: Central retinal arteriolar equivalent; CRVE: Central retinal venular equivalent; AVR: Retinal arteriole/venular Ratio; SD: Standard deviation; PX: Pixels; SBP: Systolic blood pressure; DBP: Diastolic blood pressure; Cl: Confidence intervals; $\beta$ : Beta value; ICC's: Intraclass correlation coefficients; VAMPIRE: Vessel Assessment and Measurement Platform for Images of the Retina; MABP: Mean arterial blood pressure; RMPs: Retinal microvascular parameters; Yrs: Years; MoCA: Montreal Cognitive Assessment; MCl: Mild cognitive impairment; CVD: Cardiovascular disease; CAPI: Computer-aided personal interview; GPAQ: Global Physical Activity Questionnaire; NI: Northern Ireland; MMSE: Mini-Mental State Examination; ADL: Activities of daily living: SCD: Subjective cognitive decline; DEPR: Depression; CES-D: CENTRE for Epidemiologic Studies Depression Scale questionnaire; PA: Physical activity

\section{Supplementary Information}

The online version contains supplementary material available at https://doi. org/10.1186/s12883-021-02137-4.

Additional file 1: Supplementary Table 1. Participant summary characteristics using a Montreal Cognitive Assessment score of $\leq 23$ in the presence of SCD or problems with ADL activities and the absence of DEPR. Supplementary Table 2. Summary of participant retinal microvascular parameters using a Montreal Cognitive Assessment score of $\leq 23$ in the presence of SCD or problems with ADL activities and the absence of DEPR. Supplementary Table 3. Logistic regression analysis of retinal microvascular parameters and Mild Cognitive Impairment status characterised by a Montreal Cognitive Assessment score of $\leq 23$ in the presence of SCD or problems with ADL activities and the absence of DEPR. Supplementary Table 4. Comparison of demographic characteristics between all participants with retinal fundus imaging with and without VAMPIRE retinal measures.

\section{Acknowledgements}

We are grateful to all the participants of the NICOLA Study, and the whole NICOLA team, which includes nursing staff, research scientists, clerical staff, computer and laboratory technicians, managers and receptionists. The Atlantic Philanthropies, the Economic and Social Research Council, the UKCRC Centre of Excellence for Public Health Northern Ireland, the Centre for Ageing Research and Development in Ireland, the Office of the First Minister and Deputy First Minister, the Health and Social Care Research and Development Division of the Public Health Agency, the Wellcome Trust/ Wolfson Foundation and Queen's University Belfast provide core financial support for NICOLA. The authors alone are responsible for the interpretation of the data and any views or opinions presented are solely those of the authors and do not necessarily represent those of the NICOLA Study team.

\section{Authors' contributions}

RON undertook retinal measurements, data analysis and was a major contributor to the writing of the manuscript. GMK and APM proposed the research hypothesis and were major contributors to the writing of the manuscript. FK and IY conceived and designed the NICOLA. BMG acquired and interpreted NICOLA health assessment data. $\mathrm{RH}$ acquired and interpreted NICOLA ophthalmic data. BMG, EP, SM and SC evaluated the CAPI data and characterised the case definitions. All authors revised the manuscript critically for important intellectual content; and agreed to be accountable for all aspects of the work in ensuring that questions related to the accuracy or integrity of any part of the work, were appropriately investigated and resolved. Finally, all authors read and approved the final manuscript before submission.

\section{Funding}

Rachael O'Neill was supported by a PhD studentship from the Department for Education, Northern Ireland. This work was supported by the following funders who provide core financial support for the NICOLA Study: the Atlantic Philanthropies; the Economic and Social Research Council; the UKCRC Centre of Excellence for Public Health Northern Ireland; the Centre for Ageing Research and Development in Ireland; the Office of the First
Minister and Deputy First Minister; the Health and Social Care Research and Development Division of the Public Health Agency; the Wellcome Trust/ Wolfson Foundation; and Queen's University Belfast. The authors alone are responsible for the interpretation of the data and any views or opinions presented are solely those of the authors and do not necessarily represent those of the NICOLA Study team.

\section{Availability of data and materials}

The data that support the findings of this study are available from the Northern Ireland Cohort for Longitudinal Ageing (NICOLA) but restrictions apply to the availability of this data. Data access is available by request through the NICOLA Data Access Committee (https://www.qub.ac.uk/sites/ NICOLA/InformationforResearchers/).

\section{Declarations}

Ethics approval and consent to participate

Written informed consent was obtained from participants prior to taking part following ethical approval from the Queen's University Belfast School Research Ethics Committee in compliance with the Declaration of Helsinki (SREC 12/23).

\section{Consent for publication}

Not applicable.

\section{Competing interests}

The authors declare no conflict of interest.

Received: 23 August 2020 Accepted: 3 March 2021

Published online: 11 March 2021

\section{References}

1. Harada CN, Love MCN, Triebel K. Normal cognition and aging. Clin Geriatr Med. 2013;29(4):737-52.

2. Orlove NV, Coletta C, Van Asten F, Oian Y, Ding J, Alghatrif M, et al. Agerelated changes of the retinal microvasculature. PLoS One. 2019;14(5): e0215916.

3. Gateway to Research. The Northern Ireland Cohort for longitudinal Ageing (NICOLA)-CAPI. 2013. http://gtr.rcuk.ac.uk/projects?ref=ES\%2FL008459\%2F1 Accessed $27^{\text {th }}$ Jan 2020.

4. Hedden T, Gabrieli JD. Insights into the ageing mind: a view from cognitive neuroscience. Nat Rev Neurosci. 2004:5:87-96.

5. Van Beijsterveldt CE, van Boxtel MP, Bosma H, Houx PJ, Buntinx F, Jolles J. Predictors of attrition in a longitudinal cognitive aging study: the Maastricht aging study (MAAS). J Clin Epidemiol. 2002;55:216-23.

6. Reichman WE, Fiocco AJ, Rose NS. Exercising the brain to avoid cognitive decline: examining the evidence. Aging Health. 2010;6(5):565-84.

7. Craik F, Salthouse T. The handbook of aging and cognition. 2nd ed. Mahwah: Lawrence Erlbaum; 2002.

8. Salthouse T. Consequences of age-related cognitive declines. Annu Rev Psychol. 2012;63:201-26.

9. Deary IJ, Corley J, Gow AJ, Harris SE, Houlihan LM, Marioni RE, et al. Ageassociated cognitive decline. Br Med Bull. 2009:92:132-52.

10. Klimova B, Valis M, Kuca K. Cognitive decline in normal ageing and its prevention: a review on non-pharmacological lifestyle strategies. Clin Interv Ageing. 2017;12:903-10

11. Wisdom NM, Mignogna J, Collins RL. Variability in Wechsler adult intelligence scale-IV subtest performance across age. Arch Clin Neuropsychol. 2012;27:389-97.

12. Mariani E, Monastero R, Mecocci P. Mild cognitive impairment: a systematic review. J Alzheimers Dis. 2007;12(1):23-35.

13. Nasreddine ZS, Phillips NA, Bedirian V, Charbonneau S, Whitehead V, Collin I, et al. The Montreal cognitive assessment, MoCA: a brief screening tool for mild cognitive impairment. J Am Geriatr Soc. 2005:53(4):695-9.

14. Massaldjieva RI. Differentiating normal cognitive aging from cognitive impairment No dementia: A focus on constructive and visuospatial abilities. 2018. https:/www.intechopen.com/books/gerontology/differentiatingnormal-cognitive-aging-from-cognitive-impairment-no-dementia-a-focus-onconstructive. Accessed $28^{\text {th }}$ Mar 2020. 
15. Wong TY, Klein R, Sharrett AR, Nieto FJ, Boland LL, Couper DJ, et al. Retinal microvascular abnormalities and cognitive impairment in middle-aged persons, the ARIC study. Stroke. 2002;33(6):1487-92.

16. Graham JE, Rockwood K, Beattie BL, Eastwood R, Gauthier S, Tuokko H, et al. Prevalence and severity of cognitive impairment with and without dementia in an elderly population. Lancet. 1997;349(9068):1793-6.

17. Rockwood K, Wentzel C, Hachinski V, Hogan DB, MacKnight C, McDowell I. Prevalence and outcomes of vascular cognitive impairment: vascular cognitive impairment investigators of the Canadian study of health and aging. Neurology. 2000;54(2):447-51.

18. Hachinski $V$, Munoz D. Vascular factors in cognitive impairment: where are we now? Ann N Y Acad Sci. 2000;903(1):1-5

19. Snowdon DA, Greiner LH, Mortimer JA, Riley KP, Greiner PA, Markesbery WR. Brain infarction and the clinical expression of Alzheimer disease: the Nun study. JAMA. 1997:277(10):813-7.

20. Biessels GJ, Staekenborg S, Brunner E, Brayne C, Scheltens P. Risk of dementia in diabetes mellitus: a systematic review. Lancet Neurol. 2006;5(1): 64-74.

21. Ding J, Strachan MWJ, Reynolds RM, Frier BM, Deary IJ, Fowkes FG, et al. Diabetic retinopathy and cognitive decline in older people with type 2 diabetes: the Edinburgh type 2 diabetes study. Diabetes. 2010;59(11):2883-9.

22. Witt N, Wong TY, Hughes AD, Chaturvedi N, Klein BE, Evans R, et al. Abnormalities of retinal microvascular structure and risk of mortality from ischemic heart disease and stroke. Hypertension. 2006;47(5):975-81.

23. Moody DM, Brown WR, Challa VR, Ghazi-Birry HS, Reboussin DM. Cerebral microvascular alterations in aging, leukoaraiosis, and Alzheimer's disease. Ann N Y Acad Sci. 1997;826:103-16.

24. Buee L, Hof PR, Bouras C, Delacourte A, Perl DP, Morrison JH, et al. Pathological alterations of the cerebral microvasculature in Alzheimer's disease and related dementing disorders. Acta Neuropathol. 1994;87:469-80.

25. Naidu W, Ismail K, Amiel S, Kohli R, Crosby-Nwaobi R, Sivaprsad S, et al. Associations between retinal markers of microvascular disease and cognitive impairment in newly diagnosed type 2 diabetes mellitus: a case control study. PLoS One. 2016:11(1):e0147160.

26. Patton N, Aslam T, Macgillivray T, Pattie A, Deary IJ, Dhillon B. Retinal vascular image analysis as a potential screening tool for cerebrovascular disease: a rationale based on homology between cerebral and retinal microvasculature's. J Anat. 2005:206(4):319-48.

27. Kwa VIH, van der Sande JJ, Stam J, Tijmes N, Vrooland JL. Amsterdam vascular medicine group. Retinal arterial changes correlate with cerebral small-vessel disease. Neurology. 2002;59(10):1536-40.

28. McGrory S, Ballerini L, Okely JA, Ritchie SJ, Doubal FN, Doney ASF, et al. Retinal microvascular features and cognitive change in the Lothian-birth cohort 1936. Alzheimers Dement. 2019;11:500-9.

29. Patton N, Pattie A, McGillivray T, Askam T, Dhillon B, Gow A, et al. The association between retinal vascular network geometry and cognitive ability in an elderly population. Invest Ophthalmol Vis Sci. 2007:48(5):1995-2000.

30. Liew G, Mitchell P, Wong TY, Lindley RI, Cheung N, Kaushik S, et al. Retinal microvascular signs and cognitive impairment. J Am Geriatr Soc. 2009; 57(10):1892-6.

31. Cheung CYL, Ong SY, Ikram MK, Ong YT, Chen CP, Venketasubramanian N, et al. Retinal vascular fractal dimension is associated with cognitive dysfunction. J Stroke Cerebrovasc Dis. 2014:23(1):43-50.

32. O'Neill RA, Maxwell AP, Kee F, Young I, McGuinness B, Hogg RE, et al. Association of retinal venular tortuosity with impaired renal function in the Northern Ireland cohort for the longitudinal study of ageing. BMC Nephrol. 2020;21(1):382.

33. O'Neill RA, Maxwell AP, Kee F, Young I, Hogg RE, Cruise S, McGuinness B, McKay GJ. Association of reduced retinal arteriolar tortuosity with depression in older participants from the Northern Ireland cohort for the longitudinal study of ageing. BMC Geriatr. 2021;21(1):62.

34. Radloff LS. The CES-D scale: a self-report depression scale for research in the general population. Appl Psychol Meast. 1977;1(3):385-401.

35. Metcalf KM, Baquero BI, Coronado Garcia ML, Francis SL, Janz KF, Laroche $\mathrm{HH}$, et al. Calibration of the global physical activity questionnaire to Accelerometry measured physical activity and sedentary behaviour. BMC Public Health. 2018;18:412.

36. Mumu SJ, Ali L, Barnett A, Merom D. Validity of the global physical activity questionnaire (GPAQ) in Bangladesh. BMC Public Health. 2017;17:650.
37. Fetit AE, Doney AS, Hogg S, Wang R, MacGillivray T, Wardlaw JM, et al. A multimodal approach to cardiovascular risk stratification in patients with type 2 diabetes incorporating retinal, genomic and clinical features. Sci Rep. 2019:9(1):3591.

38. McKay GJ, Paterson EN, Maxwell AP, Cardwell CC, Wang R, Hogg S, et al. Retinal microvascular parameters are not associated with reduced renal function in a study of individuals with type 2 diabetes. Sci Rep. 2018;8(1): 3931.

39. Ikram MK, Ong YT, Cheung CY, Wong TY. Retinal vascular caliber measurements: clinical significance, current knowledge and future perspectives. Ophthalmologica. 2013;229(3):125-36.

40. Ong YT, Hilal S, Cheung CYL, Xu X, Chen C, Venketasubramanian N, et al. Retinal vascular fractals and cognitive impairment. Dement Geriatr Cogn Dis Extra. 2014;4(2):305-13

41. Wu H, Wang C, Chen C, Xu X, Zhu Y, Sang A, et al. Association between retinal vascular geometric changes and cognitive impairment: a systematic review and meta-analysis. J Clin Neurol. 2020;16(1):19-28.

42. Rossetti HC, Lacritz LH, Cullum CM, Weiner MF. Normative data for the Montreal cognitive assessment (MoCA) in a population-based sample. Neurology. 2011;77(13):1272-5.

43. Roalf DR, Moberg PJ, Xie SX, Wolk DA, Moelter ST, Arnold SE. Comparative accuracies of two common screening instruments for classification of Alzheimer's disease, mild cognitive impairment, and healthy aging. Alzheimers Dement. 2013;9(5):529-37.

44. Kaya Y, Aki OE, Can UA, Derle E, Kibaroğlu S, Barak A. Validation of Montreal cognitive assessment and discriminant power of Montreal cognitive assessment subtests in patients with mild cognitive impairment and Alzheimer dementia in Turkish population. J Geriatr Psych Neur. 2014;27(2): 103-9.

45. Pinto TCC, Santos MSP, Machado L, Bulgacov TM, Rodrigues-Junior AL, Silva GA, et al. Optimal cut-off scores for dementia and mild cognitive impairment in the Brazilian version of the Montreal cognitive assessment among the elderly. Dement Geriatr Cogn Dis Extra. 2019;9:44-52.

46. Milani SA, Marsiske M, Cottler LB, Chen X, Striley CW. Optimal cutoffs for the Montreal cognitive assessment vary by race and ethnicity. Alzheimers Dement. 2018:10:773-81.

47. Carson N, Leach L, Murphy KJ. A re-examination of Montreal cognitive assessment (MoCA) cut-off scores. Int J Geriatr Psychiatry. 2018:33(2):379-88.

48. Gatto NM, Varma R, Torres M, Wong TY, Johnson PL, Segal-Gidan F, et al. Retinal microvascular abnormalities and cognitive function in Latino adults in Los Angeles. Ophthalmic Epidemiol. 2012;19(3):127-36.

49. Wong TY, Knudtson MD, Klein BE, Meuer SM, Hubbard LD. Computerassisted measurement of retinal vessel diameters in the beaver dam eye study: methodology, correlation between eyes, and effect of refractive errors. Ophthalmology. 2004;111(6):1183-90.

50. Cheung N, Tikellis G, Saw SM, Amirul Islam FM, Mitchell P, Wang JJ, et al. Relationship of axial length and retinal vascular caliber in children. Am J Ophthalmol. 2007;144(5):658-62.

51. Leung H, Wang JJ, Rochtchina E, Tan AG, Wong TY, Hubbard LD, et al. Computer-assisted retinal vessel measurement in an older population: correlation between right and left eyes. Clin Exp Ophthalmol. 2003;31(4): 326-30

52. Tyrovolas S, Koyanagi A, Lara E, Santini ZI, Haro JM. Mild cognitive impairment is associated with falls among older adults: findings from the Irish longitudinal study on ageing (TILDA). Exp Gerontol. 2016;75:42-7.

53. Trzepacz PT, Hochstetler H, Wang S, Walker B, Saykin AJ. Relationship between the Montreal cognitive assessment and mini-mental state examination for assessment of mild cognitive impairment in older adults. BMC Geriatr. 2015;15:107

54. Folstein MF, Folstein SE, McHugh PR. "Mini-mental state". A practical method for grading the cognitive state of patients for the clinician. J Psychiatr Res. 1975;12(3):189-98.

55. Luis CA, Keegan AP, Mullan M. Cross validation of the Montreal cognitive assessment in community dwelling older adults residing in the south eastern US. Int J Geriatr Psych. 2009;24(2):197-201.

56. Freitas S, Simões MR, Alves L, Santana I. Montreal cognitive assessment: validation study for mild cognitive impairment and Alzheimer disease. Alzheimer Dis Assoc Disord. 2013:27(1):37-43.

57. Nazem S, Siderowf AD, Duda JE, Have TT, Colcher A, Horn SS, et al. Montrea cognitive assessment performance in patients with Parkinson's disease with 
"normal" global cognition according to mini-mental state examination score. J Am Geriatr Soc. 2009;57(2):304-8.

58. Lam B, Middleton LE, Masellis M, Stuss DT, Harry RD, Kiss A, et al. Criterion and convergent validity of the Montreal cognitive assessment with screening and standardized neuropsychological testing. J Am Geriatr Soc. 2013;61(12):2181-5.

59. Yates JA, Clare L, Woods RT, MRC CFAS. Subjective memory complaints, mood and MCl: a follow-up study. Aging Ment Health. 2017;21(3):313-21.

60. Cornelis E, Gorus E, Beyer I, Bautmans I, De Vriendt P. Early diagnosis of mild cognitive impairment and mild dementia through basic and instrumental activities of daily living: development of a new evaluation tool. PLoS Med. 2017;14(3):e1002250.

61. Lopez OL, Jagust WJ, DeKosky ST, Becker JT, Fitzpatrick A, Dulberg C, et al. Prevalence and classification of mild cognitive impairment in the cardiovascular health study cognition study: part 1. Arch Neurol. 2003, 60(10):1385-9.

62. Kumar R, Dear KB, Christensen H, Ilschner S, Jorm AF, Meslin C, et al. Prevalence of mild cognitive impairment in 60- to 64-year-old community dwelling individuals: the personality and Total health through life 60+ study. Dement Geriatr Cogn Disord. 2005;19(2-3):67-74.

\section{Publisher's Note}

Springer Nature remains neutral with regard to jurisdictional claims in published maps and institutional affiliations.

Ready to submit your research? Choose BMC and benefit from:

- fast, convenient online submission

- thorough peer review by experienced researchers in your field

- rapid publication on acceptance

- support for research data, including large and complex data types

- gold Open Access which fosters wider collaboration and increased citations

- maximum visibility for your research: over $100 \mathrm{M}$ website views per year

At BMC, research is always in progress.

Learn more biomedcentral.com/submissions 